\title{
Spray drying of mango juice - buttermilk blends
}

\author{
Ramachandra H.G. RAO*, Arun H. KUMAR \\ Department of Dairy Technology, Dairy Science College, Karnataka Veterinary, Animal and Fishery \\ Sciences University, Hebbal, Bangalore-560 024, India
}

Published online 5 July 2005

\begin{abstract}
In India both dairy and fruit sectors face problems of lack of basic infrastructure for handling peaks in production. Mango is considered as king of the fruits, but its production is highly seasonal. Lack of adequate infrastructure in many places results in huge losses due to low keeping quality. In the dairy industry, buttermilk, a by-product of butter production, is mostly left unutilized. Buttermilk is a good source of valuable milk proteins and lactose; its high phospholipids content makes dried buttermilk a good functional ingredient in food formulations. In this study, blends with different levels of mango juice and buttermilk were spray dried viz., 5:95, 10:90, 15:85 and 20:80 at feed temperature of $40-55^{\circ} \mathrm{C}$ and compressed air pressure of $68-170 \mathrm{kPa}$. It was observed that the various processing parameters such as outlet air temperature, total solids and blend proportions had a profound effect on the characteristics of the resultant powder. The viscosity of blends increased with an increase in the mango juice proportion in the blend. High acid content of the blends had no negative effect on thermal stability of the blends before and after spray drying. This is probably due to the fact that a relatively low feed temperature $\left(45^{\circ} \mathrm{C}\right)$ was used and the exposure of the blends to high temperatures was only momentary during drying process. It was found that increments in the inclusion of mango solids had a positive effect on the resultant yield of powder. An increase in solid content of the blends up to $35 \%$ resulted in a steep increase in yield, which was adjudged as the optimal total solids for drying. Further increase in total solids of the blends resulted in reduced yields. The outlet air temperatures of the spray drier were optimized at a range of $85-90{ }^{\circ} \mathrm{C}$ for all the blends. Sensory evaluation studies by an in-house panel affirmed that the blend with 20:80 ratio of mango juice: buttermilk, respectively, possessed the desired sensory characteristics.
\end{abstract}

spray drying / buttermilk / mango juice / juice-milk blends / Kulfi

Résumé - Séchage par atomisation de mélanges de jus de mangue et de babeurre. En Inde, le secteur laitier et la production fruitière rencontrent les mêmes problèmes de manque d'infrastructure pour traiter les pics de production. Ceci est vrai pour la mangue, fruit roi, mais dont la production hautement saisonnière conduit, faute d'infrastructures adéquates pour sa conservation, à des pertes considérables. C'est aussi le cas dans l'industrie laitière où les surplus saisonniers de lait sont écrémés puis séchés, tandis que la crème est transformée en beurre, seul report pour la basse saison. Le babeurre, sous-produit de cette production, riche en protéines et en lactose, reste la plupart du temps inutilisé. Sa teneur élevée en phospholipides en fait, après séchage, un bon ingrédient fonctionnel pour la formulation d'aliments. Dans cette étude, des mélanges à différents taux de jus de mangue et de babeurre $(5: 95,10: 90,15: 85$, et 20:80) ont été séchés par atomisation, à des températures d'entrée de $40-55^{\circ} \mathrm{C}$, et des pressions de $68-170 \mathrm{kPa}$. Il a été observé que les différents paramètres opératoires tels que la température de sortie d'air, la teneur en matière sèche et les proportions dans le mélange avaient un effet important sur les caractéristiques de la poudre résultante. Plus la proportion de jus de mangue dans le mélange augmentait, plus la viscosité augmentait. La teneur élevée en acide des mélanges n'avait pas d'effet négatif sur la stabilité thermique des mélanges avant et

* Corresponding author: hgrrao@yahoo.com 
après séchage. Ceci est probablement dû au fait qu'une température d'entrée relativement basse $\left(45^{\circ} \mathrm{C}\right)$ a été utilisée et que l'exposition des mélanges à des températures élevées n'était que momentanée au cours du séchage. L'ajout de mangue avait un effet positif sur le rendement de poudre obtenu. Une augmentation forte du rendement était obtenue lorsque qu' on élevait la teneur en matière sèche des mélanges jusqu'à $35 \%$, valeur retenue comme optimale pour le séchage. Au-delà de ce taux, les résultats s'inversaient. Les températures de sortie d'air dans la tour de séchage étaient optimales dans la gamme $85-90{ }^{\circ} \mathrm{C}$ pour tous les mélanges. Les analyses sensorielles réalisées par un panel interne ont évalué le mélange jus de mangue:babeurre 20:80 comme étant le meilleur.

séchage par atomisation / babeurre / jus de mangue / mélange lait-jus de fruit / Kulfi

\section{INTRODUCTION}

India is the world's largest milk producing country with an estimated output of 84 million tons in 2004. This phenomenal rise in milk production is not well supported by the existing infrastructure in India to handle fluid milk. The processing plants and associated chilling centers in many instances are handling quantities above their rated capacities. Seasonal surplus milk is conserved by separating milk, subsequently cream is used for making butter, which is then stored for lean season. This milk can effectively be converted into milk powder, which acts as a milk balance during the lean season to meet consumer demands and exports. Buttermilk, a by-product of butter production, is mostly left unutilized. Similarly, in fruit and vegetable sectors in many developing countries there are reports of high losses. In India alone an estimated loss of around 35000 million Indian Rupees (around 638 million US \$) worth of fruits and vegetables was recorded despite the fact that India produces around 60 to 65 million tons of fruits and vegetables [6]. This problem largely persists in India due to overproduction, lack of planning for packaging and distribution besides inadequate infrastructure to store the fruit in its natural state. The cost of storage is very high and refrigeration capacity is inadequate. Mango is called the king of fruits in India and it is a very good source of sugars, vitamins and minerals. India is the largest producer of mango; its annual production is about 12 million tons. There is great demand for good quality mango in the world, particularly Alphanso variety. Like many tropical fruits, mango production is also seasonal, reaching peak production between March and July. During this season there is a lot of wastage of fruits, due to lack of basic infrastructure such as storage facilities, distribution network and adequate and cheaper technology. In this regard, preservation of mango juice solids in some form will help to stabilize prices and prevent wastage. Further, making blends of buttermilk and mango juice solids and spray drying them will help to overcome problem of buttermilk utilization and products prepared by using this dried blend will be rich in vitamin $\mathrm{C}$.

Since the number of studies concerning utilization and conservation of these products in combination is limited [2], an attempt is made here to investigate the application of spray drying techniques. Keeping this in view, the broad objectives of the project were:

- To optimize the processing parameters for production of Mango juice buttermilk blended powder.

- To study the physico-chemical and sensory characteristics of the resultant powders.

- To study the storage stability of the product.

- To study the effect of incorporating mango-buttermilk solids on physicochemical and sensory characteristics of Kulfi, a traditional Indian product.

\section{MATERIALS AND METHODS}

\subsection{Materials}

\subsubsection{Mango juice - buttermilk blends}

Mango juice concentrate was procured from local markets in Bangalore, India with 
about $60 \%$ total solids. Buttermilk was produced from the Student Experimental Dairy Plant, Dairy Science College, Bangalore, Karmataka Veterinary, Animal and Fishery Sciences University. Buttermilk was condensed using a pilot scale Anhydro evaporator (Anhydro, Copenhagen, Denmark) at temperatures between $55-60{ }^{\circ} \mathrm{C}$ with vacuum of $53 \mathrm{~Pa}$, to one-third of the original volume to obtain a level in total solids between $30-35 \%$. The experimental samples of mango juice - buttermilk blends were made by blending mango juice concentrate with condensed buttermilk for convenience in the following proportions: 5:95, 10:90, $15: 85$, and $20: 80$ of mango juice and buttermilk, respectively, at temperatures not exceeding $45^{\circ} \mathrm{C}$. An empirical formula was devised to make blend proportions in terms of ratios of mango juice: buttermilk blends. In order to obtain a good quality mango juice - buttermilk blended powder, various combinations of processing parameters were studied. The blends were dried using a pilot scale Anhydro two-fluid nozzle spray drier at various levels in total solids (TS), viz., 20, 25, 30 and 35\% and inlet temperatures of $75-80,80-85$, and $85-90{ }^{\circ} \mathrm{C}$. The drier had a water evaporation capacity of $7-8 \mathrm{~kg} \cdot \mathrm{h}^{-1}$. Before feeding to the drier, it was ensured that the inlet air temperature was stabilized at $180^{\circ} \mathrm{C}$. The outlet air temperature was maintained at desired levels by manipulating the compressed air pressure, in combination with adjustment of the feed rate. To standardize the compressed air pressure and feed temperature, 20:80 blends were spray dried at $30 \%$ TS. The compressed air pressures employed were 0.068-0.102 MPa, 0.108-0.136 $\mathrm{MPa}$, and 0.14-0.17 MPa, with feed temperatures of $40,45,50$ and $55^{\circ} \mathrm{C}$. The standard control for the study was that of 0:100 (pure skim milk) dried at $30 \%$ TS and its yield was considered as $100 \%$ (only for purpose of comparison). In this investigation, relative yield above $70 \%$ was considered as satisfactory output, whereas those below $70 \%$ were considered as low. The batch size for all the trials was $1.5 \mathrm{~kg}$ of the blend (feed).

From the various samples that were obtained during the process optimization trials, representative samples of the 4 pro- portions having the best attributes were selected based on organoleptic and quantitative observations. These representative powder samples were subjected to various physico-chemical and sensory attributes. A panel of 5 trained judges performed sensory evaluation.

\subsubsection{Kulfi}

Kulfi (or Malai Kulfi), known as Indian ice cream, is an indigenous frozen dairy product. It closely resembles ice cream in composition, is a highly palatable and nutritious frozen dessert and largely produced in the unorganized sector in small quantities. It is produced by concentrating whole milk two-fold (2:1) by direct heating in an open pan to remove moisture, until a TS level of about $26 \%$ is reached. Other ingredients are then added as sugar (about $13 \%$ by weight of concentrated milk, stabilizers (sodium alginate $0.3 \%$ ) and emulsifiers (glycerol mono-stereate $0.2 \%$ ), followed by addition of some optional ingredients such as colours, flavours, nuts such as almonds, pista, etc. The mix is then filled into moulds and hardened in a deep freezer at $-20{ }^{\circ} \mathrm{C}$ for about $8 \mathrm{~h}$. In this study, spray-dried mango juice - buttermilk powder was incorporated into milk at the rates of 2,3 , or $4 \%$ by weight of Kulfi mix at the point of addition of flavours, colours and nuts and further the mix was filled into moulds and hardened like control Kulfi (detailed flow diagram is given in Fig. 1).

\subsection{Methods}

\subsubsection{Penetration value}

A universal penetrometer supplied by Associated Instrument Manufacturers Limited, (Kolkota, India) with graduated dial (AIM 019 make) and automatic penetrometer timer was used to determine hardness of Kulfi samples.

The hardness of Kulfi samples were measured as soon as they are drawn from deep freezer $\left(-20^{\circ} \mathrm{C}\right)$. A cone and test rod (probe) weighing $10.23 \mathrm{~g}$ was allowed to penetrate Kulfi samples for a fixed time of $5 \mathrm{~s}$. The reading was taken at 3 spots of each 




Figure 1. Flow diagram for preparation of control Kulfi. sample and average value was taken as the penetration per $5 \mathrm{~s}$.

\subsubsection{Melting time}

Melting time of Kulfi was measured taking one mould at a time. Ten grams of hardened Kulfi sample were drawn from a mould and transferred to middle of a Petri plate and kept for melting at room temperature $\left(25-27^{\circ} \mathrm{C}\right)$. The total time taken by Kulfi sample to melt completely was noted as melting time in minutes [1].

\subsubsection{Moisture content (\%)}

The moisture content of powders was estimated as per the procedure described in Indian Standards Institution [4]. Five grams of powder was accurately weighed into an aluminum dish with a cover previously dried and weighed. The dish containing the powder was heated uncovered in an oven at $98 \pm 2{ }^{\circ} \mathrm{C}$ and cooled in a desiccator. The weight was taken with the cover on. The process of drying was repeated every $3 \mathrm{~min}$ until consecutive results showed not more than $1 \mathrm{mg}$ difference. The $\%$ moisture was calculated from the loss of mass.

\subsubsection{Packed bulk density $\left(g \cdot m L^{-1}\right)$}

The tare weight of the 100-mL cylinder was determined. The powders were consolidated by tapping on a rubber mat until the volume was reduced and reasonably constant. The volume of the powder was read in $\mathrm{mL}$ and bulk density recorded as $\mathrm{g} \cdot \mathrm{mL}^{-1}$.

\subsubsection{Insolubility index $(m L)$}

Fourteen grams of powder sample was taken and added to $1000 \mathrm{~mL}$ distilled water and stirred for $90 \mathrm{~s}$. The foam was removed manually using a spoon after keeping aside the mixture for some time. Centrifuge tubes were filled with reconstituted sample to the $50-\mathrm{mL}$ mark and centrifuged for $5 \mathrm{~min}$. Immediately the transparent liquid was siphoned out to within $5 \mathrm{~mL}$ of the sediment level taking care not to disturb it. Twenty five $\mathrm{mL}$ of distilled water was added to it at $24{ }^{\circ} \mathrm{C}$ and shaken to dislodge it. The tube was filled to the $50-\mathrm{mL}$ mark with distilled 
Table I. Effect of feed temperature and compressed air pressures on the yields of powders.

\begin{tabular}{lcccc}
\hline Compressed air pressures & \multicolumn{4}{c}{ Feed temperatures } \\
\cline { 2 - 5 } & $40{ }^{\circ} \mathrm{C}$ & $45^{\circ} \mathrm{C}$ & $50{ }^{\circ} \mathrm{C}$ & $55{ }^{\circ} \mathrm{C}$ \\
\hline $10-15$ PSI & LO, CK & LO & LO & LO, CL \\
$(0.068-0.102 \mathrm{MPa})$ & SO, CK & SO & LO & LO, CL \\
$\begin{array}{l}16-20 \text { PSI } \\
(0.108-0.136 \mathrm{MPa})\end{array}$ & HP & HP & HP & HP \\
$21-25 \mathrm{PSI}$ & & & & \\
$(0.14-0.17 \mathrm{MPa})$ & & &
\end{tabular}

CL - Clogging of the nozzles.

CK - Caking.

HP - Unacceptable High Pressure considering drying chamber height constraint.

LO - Low output $(<70 \%$ relative yield).

SO - Satisfactory output ( $>70 \%$ relative yield).

All samples were 20:80 blends with $30 \%$ TS.

water and centrifuged again for $5 \mathrm{~min}$. The tube was held in a vertical level and milliliters of sediment was noted which included the solubility index.

\subsubsection{Dispersability}

The powders were reconstituted to $10 \%$ TS level and dispersability for this level of reconstitution was calculated by the following formula suggested by Upadhyay [12].

$\mathrm{D}=\mathrm{T} \times 735 / 100-(\mathrm{W}+\mathrm{T})$

$\mathrm{D}=$ Dispersability $\%$

$\mathrm{T}=$ Total solids of the reconstituted liquid after filtration

$\mathrm{W}=$ Moisture \% of the milk powder.

\subsubsection{Particle size}

The particle size of the powders was determined by using a microscope in the microbiology lab.

\subsubsection{Sensory evaluation}

The mango juice - buttermilk blended powder and Kulfi samples were judged in the sensory evaluation lab by an in-house panel consisting of 5 experienced judges of the university. The panelists were supplied with both powder as well as reconstituted form of mango-buttermilk blends. In case of reconstituted form, the powder was fully dispersed in warm water at $40{ }^{\circ} \mathrm{C}$ to a solid level of $10 \%$ and supplied to judges.

\subsubsection{Statistical analysis}

Results of the study were analyzed both as randomized column block design and multiple factorial designs as per methods described by Snedecor and Cochran [10] to test statistical significance. Critical difference (CD) was calculated to determine whether the treatment means were similar or not. The analysis was done using SPSS software package and MS Excel 2000.

\section{RESULTS AND DISCUSSION}

The effect of various parameters such as blend proportions, feed temperature, compressed air pressure, TS of the feed and outlet temperature on the relative yield of the resultant powder was studied.

\subsection{Feed temperature and compressed air pressure}

The effect of compressed air pressure and feed temperatures are given in Table I. From the table it is clear that the most acceptable feed temperature was $45^{\circ} \mathrm{C}$ at an air pressure range of $0.108-0.136 \mathrm{MPa}$. It 
Table II. Effect of total solids on the relative yields of Mango juice-buttermilk blended powders.

\begin{tabular}{lc}
\hline Total Solids & Relative Yield (\%) \\
\hline 20 & $26.27^{\mathrm{a}}$ \\
25 & $48.69^{\mathrm{b}}$ \\
30 & $65.72^{\mathrm{d}}$ \\
35 & $66.25^{\mathrm{c}}$ \\
Critical Difference & 0.89 \\
Correlation Coefficient & 0.89 \\
\hline
\end{tabular}

Values indicated are mean values of 3 replications. Within a column, mean values bearing at least one common superscript are statistically similar $(P<0.05)$.

can be noted that higher air pressures $(0.14$ $0.17 \mathrm{MPa}$ ) were not acceptable at all levels of feed temperature. Feed temperature above $50{ }^{\circ} \mathrm{C}$ at compressed air pressure of 0.068-0.102 $\mathrm{MPa}$ and 0.108-0.136 $\mathrm{MPa}$ resulted in clogging of nozzle during the operation. High feed temperature of the blends $\left(>50^{\circ} \mathrm{C}\right)$ caused an increase in viscosity, resulting in clogging of the spray nozzle. This is consistent with the advice of Masters [5], who stated that droplet size varies directly with feed liquid viscosity. On the other hand, feed temperature below $45^{\circ} \mathrm{C}$ encountered caking problems at compressed air pressure ranges of 0.0680.102 and $0.108-0.136 \mathrm{MPa}$.

It is noted that droplet size is related to the change in density and surface tension during viscosity changes of feed at a constant feed rate and nozzle pressure. Other workers $[3,5]$ found that an increase in viscosity resulted in larger particle size, which subsequently reduced the surface area between the droplet and drying medium (hot air) resulting in improper drying of the product. Hence a lower feed temperature of $45^{\circ} \mathrm{C}$ was employed in this study. The compressed air pressure was optimized to $0.108-0.136 \mathrm{MPa}$ after preliminary studies. To overcome the problem of development of high viscosity of the feed, a reduction in the TS level with or without an increase in the temperature of the feed is suggested [5]. In this study the situation was found to be
Table III. Moisture percentage of the Mango juice - buttermilk blended powders.

\begin{tabular}{lc}
\hline Proportion of blends & Moisture (\%) \\
\hline Control & $3.81^{\mathrm{a}}$ \\
$5: 95$ & $4.32^{\mathrm{b}}$ \\
$10: 90$ & $4.75^{\mathrm{e}}$ \\
$15: 85$ & $4.97^{\mathrm{c}}$ \\
$20: 80$ & $5.22^{\mathrm{d}}$ \\
Critical Difference & 0.1398 \\
Correlation Coefficient & 0.92 \\
\hline
\end{tabular}

Values indicated are mean values of 3 replications. Spray drying was carried out at inlet and outlet air temperatures of $180^{\circ} \mathrm{C}$ and $80-85^{\circ} \mathrm{C}$ respectively and Total solid level of $30 \%$ in the feed was maintained.

Within a column, mean values bearing at least one common superscript are statistically similar $(P<0.05)$.

much more complex to accept these conventional methods. Hence feed temperatures were maintained at relatively low levels since it was a highly acidic product.

\subsection{Effect of total solids}

The effect of TS of feed on the relative yield is recorded in Table II. It may be noted from the table that \% TS of the feeds has a significant effect $(P<0.05)$ on the relative yield of the powder. As TS increased in the feed, the relative yield also increased, the highest yield was obtained at 35\% TS and lowest recorded at $20 \%$ TS level. The increased yield as a result of an increase in TS confirmed the trends indicated by earlier work [11], which reported that an increase in TS in condensed milk proportionally improved the spray drying process of milk with the only constraint being viscosity of feed on the spray drying process.

\subsection{Effect of proportion of blends on moisture percentage of resultant powders}

The effect of variation in proportion of mango juice and buttermilk on moisture $\%$ of resultant spray dried powder was recorded in Table III. It can be observed from the 
Table IV. Effect of blending Mango juice with buttermilk on bulk density and insolubility index of the resultant powders.

\begin{tabular}{lcc}
\hline Proportion of blend & Bulk density $\left(\mathrm{g} \cdot \mathrm{mL}^{-1}\right)$ & Insolubility index $(\mathrm{mL})$ \\
\hline Control & $0.44^{\mathrm{a}}$ & 1.0 \\
$5: 95$ & $0.49^{\mathrm{b}}$ & 1.9 \\
$10: 90$ & $0.51^{\mathrm{c}}$ & 2.2 \\
$15: 85$ & $0.55^{\mathrm{d}}$ & 2.7 \\
$20: 80$ & $0.64^{\mathrm{e}}$ & 3.8 \\
Critical Difference & 0.0294 & 0.241 \\
Correlation Coefficient & 0.96 & 0.85
\end{tabular}

Within a column, means bearing at least one common superscript are statistically similar $(P<0.05)$. Yields indicated are mean values of 3 replications.

Spray drying was carried out at inlet and outlet air temperatures of 180 and $80-85{ }^{\circ} \mathrm{C}$ respectively. All blends were dried at the outlet temperature range of $80-85^{\circ} \mathrm{C}$.

table that as the proportion of mango juice increased the moisture $\%$ of the powder also increased. The lowest moisture of $3.81 \%$ was recorded for the control and highest moisture of $5.22 \%$ was recorded for $20: 80$ blends. The higher moisture $\%$ in 20:80 blends may partly be attributed to the lower feed temperatures used in these experiments. The results are in accordance with earlier work [5], where lower feed temperatures resulted in higher requirements of heat to produce a unit weight of dried product leading to an increase in the moisture $\%$ of resultant powders. The two-fluid/pneumatic nozzle system used in the study also contributed to the higher moisture levels in the powders. It may be noted here that pressures of the pneumatic nozzle result in variation in the mean particle size of the atomized feed of high viscosity. Further, low pressures would produce higher mean particle size, resulting in reduced drying efficiency and higher moisture in the resultant powders. Moreover, the hygroscopic nature of mango juice attributed to the fruit sugars also contributed to high moisture content as the levels of juice increased in the feed.

\subsection{Effect of blend proportions on bulk density and insolubility index of resultant powders}

Table IV depicts the effect of blend proportion on the bulk density and insolubility index of powders. It may be observed from the table that as the proportion of mango juice increased in the blends from 5:95 to 20:80, the bulk density also increased. The control recorded lowest bulk density and 20:80 blends recorded highest value. There were several factors in this study that have contributed to the increase in the bulk densities. One such major factor was the employment of lower feed temperatures. In this context, increasing feed temperature contributes to improved atomization by forming spherical droplets instead of threadlike streams due to reduction in feed viscosity [5]; an increase in bulk density is also observed. This explained the increase in the bulk density of the blends at higher levels of mango juice solids. Further, it may be noted that the resultant powders on the whole possessed normal bulk density levels ranging between $0.5-0.8 \mathrm{~g} \cdot \mathrm{mL}^{-1}$ as indicated by Upadhyay [12], except for the control and 5:95 blend. According to Mettler [7], reducing the total solids of the feed lowers the bulk density of the resultant powder. This accounted mainly for the relatively lower bulk density in the powders with lower mango proportions. Spray-dried fiber-containing fruits including mango underwent the greatest increase in bulk density due to particle rearrangement, hence, an increase in bulk densities among blends with increasing proportion of mango solids [2]. 
Table V. Sensory evaluation of Mango juice - buttermilk blended powder.

\begin{tabular}{lccc}
\hline Proportion of blend & $\begin{array}{c}\text { Flavour score } \\
\text { (Max 65) }\end{array}$ & $\begin{array}{c}\text { Appearance score } \\
\text { a) (Max 15) }\end{array}$ & $\begin{array}{c}\text { Appearance score } \\
\text { b) (Max 15) }\end{array}$ \\
\hline $5: 95$ & 54.2 & 10.8 & 11.5 \\
$10: 90$ & 56.8 & 11.0 & 12.3 \\
$15: 85$ & 58.2 & 12.6 & 13.6 \\
$20: 80$ & 57.8 & 14.1 & 13.5 \\
\hline
\end{tabular}

a) dry.

b) reconstituted.

Values indicated are means of the scores provided by a panel of 5 judges.

Table VI. Effect of incorporation dried mango juice - buttermilk powder (\% of Kulfi mix) on melting time and penetration value of Kulfi.

\begin{tabular}{lcc}
\hline $\begin{array}{l}\text { Rate of } \\
\text { incorporation (\%) }\end{array}$ & $\begin{array}{c}\text { Melting } \\
\text { Time (min) }\end{array}$ & $\begin{array}{c}\text { Penetration Value } \\
(\mathrm{mm} / 5 \mathrm{~s})\end{array}$ \\
\hline Control (0\%) & 28.5 & 57.6 \\
2 & 28.3 & 58.1 \\
3 & 28.0 & 58.8 \\
4 & 27.2 & 59.2 \\
Critical difference & 0.42 & 0.53 \\
\hline
\end{tabular}

The effect of blend proportions on insolubility index is presented in Table IV. It may be noted that control recorded lowest insolubility index and as the proportion of mango juice in the blend increased, the insolubility index also increased. In this regard, acidity has a profound effect on insolubility index of milk powders [9]. As the mango juice proportion increased, the acidity of the blend also increased, resulting in higher insolubility index of the resultant powders.

\subsection{Sensory evaluation of the mango juice - buttermilk blended powders}

A panel of 5 in-house judges evaluated the powder samples of various proportions of mango juice:buttermilk. From Table V it may be observed that the powder produced from 15:85 blends was adjudged to be the best quality product among the various optimized blends. It is also clear that the flavour scores were higher in 15:85 blend of powder, while the lowest score was recorded for the 5:95 blends. Further, it may be deduced that blends containing mango solids $>15: 85$ showed a reduction in the flavour score. General comments by the judges suggested that the 15:85 had a very pleasing and optimal flavour level, while the blend with higher mango solids than 15:85 was less acceptable due to strong aftertaste. The judges felt that 5:95 and 10:90 lacked distinct mango flavour. The dry appearance scores for the various powders indicated highest scores with 20:80 and lowest scores against the 5:95 blends. The general perception of the 15:85 powder was that it had an attractive lighter yellow colour, free of lumps and scorched particles. The immediate second choice was that of 20:80 although it was observed to have slightly darker colour. The reconstituted appearance scores of the powders suggested that both 15:85 and 20:80 had almost the same high scores. The lowest scores were obtained by 5:95 and 10:90.

\subsection{Effect of incorporation of dried mango juice - buttermilk powder on melting time and hardness of Kulfi}

From Table VI it may be observed that there was no significant difference between the melting time of control and $2 \%$ level of incorporation. However, at 3 and $4 \%$ levels there was small, but significant difference 
Table VII. Effect of incorporation of dried mango juice - buttermilk on sensory evaluation of Kulfi.

\begin{tabular}{lccccc}
\hline $\begin{array}{l}\text { Rate of incorporation } \\
(\%)\end{array}$ & $\begin{array}{c}\text { Flavour } \\
(10)\end{array}$ & $\begin{array}{c}\text { Body \& Texture Colour \& Appearance } \\
(5)\end{array}$ & $\begin{array}{c}\text { Melting } \\
\text { quality }\end{array}$ & $\begin{array}{c}\text { Overall } \\
\text { acceptability }\end{array}$ \\
\hline Control (0\%) & 9.34 & 4.7 & 4.4 & 4.0 & 22.44 \\
2 & 9.7 & 4.5 & 4.3 & 4.1 & 22.60 \\
3 & 9.62 & 4.3 & 4.1 & 3.8 & 21.82 \\
4 & 9.1 & 4.1 & 3.8 & 3.5 & 20.5 \\
\hline
\end{tabular}

in the melting time as compared to the control. The penetration values of treated Kulfi samples were higher than control, indicating that treated Kulfi had softer body than the control. But there was no significant difference in penetration values between control and $2 \%$ incorporation. These results indicate that $2 \%$ level of incorporation of dried mango-buttermilk blends had no significant effect on both melting time and hardness of Kulfi.

\subsection{Effect of incorporation of dried mango juice - buttermilk blends on sensory evaluation of Kulfi}

Table VII records the effect of incorporating dried mango juice - buttermilk blends on sensory evaluation of Kulfi. It can be seen from the table that in flavour attribute, 2 and $3 \%$ levels of incorporation scored higher than that of control. But at $4 \%$ flavour scores of treated Kulfi was lower than that of control. At 2 and 3\% levels, Kulfi had rich pleasing flavour of mango, very much liked by the judges. But at $4 \%$ level, the judges indicated that the flavour of Kulfi was very strong. In body and textural attribute, scores of all treated Kulfi were lower than that of control and as the \% incorporation increased, the scores recorded were also lower. This according to the judges was due to slightly excessive softness of the treated product as compared to the control. But judges felt that the body of Kulfi at $2 \%$ level was almost comparable to that of control.

In colour and appearance attribute, control Kulfi scored highest and among the treated Kulfi, as the level of incorporation increased, the colour and appearance score decreased. This is probably because the judges did not liked dark mango colour of treated Kulfi samples.

The melting quality of $2 \%$ level Kulfi was slightly better than that of control. But at 3 and $4 \%$ levels, the melting qualities of treated Kulfi samples were lower than that of control and also 2\% level. Finally in overall acceptability scores, $2 \%$ treated Kulfi samples scored the highest scores, followed by control, 3 and $4 \%$. But the difference in overall acceptability scores between control and 2\% was not significant. Low overall acceptability scores in 3 and $4 \%$ levels of incorporation were due to lower body and textural and melting quality scores awarded to these samples of Kulfi by the judges.

\section{CONCLUSION}

It was found that various processing parameters such as outlet air temperature, TS level in feed, compressed air pressure (feed rate) and blend proportions have profound effect on the output and quality of powder obtained during spray drying. Among different combinations of compressed air pressures and feed temperatures tried, feed pressures of $0.108-0.136 \mathrm{MPa}$ and feed temperature of $45^{\circ} \mathrm{C}$ gave satisfactory output. Among various levels of solid levels tried in the blend, $35 \%$ was found to give maximum yield. As the proportion of mango juice increased, the moisture percentage, bulk density, insolubility index of powder also increased. Sensory evaluation of formulated powder indicated that the mango flavour was retained in all the powders. In general, 20:80 blends had desired characteristics as 
judged by the panelists. The resultant powder could be incorporated up to $2 \%$ in Indian ice cream, Kulfi, without compromising the other desirable characteristics of the product. Further, incorporation of dried mango juice buttermilk blends at $2 \%$ not only improved the flavour of Kulfi, but also imparted softness and mellowness to the product. The overall acceptability of Kulfi at $2 \%$ level of incorporation was similar to control Kulfi.

The physico-chemical properties of defining optimal spray dried 20:80 mango juice buttermilk powder are:

1. Appearance: uniform colour light yellow with no dark specks or burnt/ scorched particles. The resultant powder is not very hygroscopic, showing smooth surface without wrinkles with usual spherical surface.

2. Moisture content between 4-5\%.

3 . Reconstitutability in water is reasonably high.

4. Acidity between $280-320 \mathrm{meq} \cdot \mathrm{g}^{-1}$ with corresponding $\mathrm{pH}$ of 5.7-6.1.

5. Particle size between $110-260 \mu \mathrm{mol} \cdot \mathrm{L}^{-1}$.

6. Optimum packed bulk density of $0.51-0.65 \mathrm{~g} \cdot \mathrm{mL}^{-1}$.

7. Insolubility index not exceeding $2.5 \mathrm{~mL}$.

8. Dispersibility not less than $85 \%$.

9. Yield: satisfactory yield as compared to that obtained by spray drying control skim milk powder.

It may be concluded that:

- Both mango and buttermilk have very limited shelf life, drying them alone or in combination increased keeping quality and applications in formulated foods.

- Combination of mango juice and buttermilk provides high nutritional value and functionality to formulated foods.

- Value addition: it was found that in some traditional Indian dairy products, the formulated powder had very positive effect on acceptability by the consumers.

- Further research is required to study the effect of incorporation of powder on rheological characteristics and keeping quality of traditional dairy products.

- The formulated powder may also be tried with many other formulated foods such as infant foods and desserts.

\section{REFERENCES}

[1] Arbuckle W.S., Ice cream, 4th edn., The AVI publication Co. Inc., West port, Connecticut, USA, 1986.

[2] Breene W.M., Coulter S.T., Properties of spray dried combinations of milk, fruits and vegetables, J. Dairy Sci. 50 (1967) 1049-1053.

[3] De Vilder J., Martens R., Naudts M., The influence of the dry matter content, the homogenization and the heating of concentrate on physical characteristics of whole milk powder, Milchwissenschaft 34 (1979) 78-84.

[4] ISI hand book of food analysis, Part XI, Dairy Products, Indian Standards Institute, Manak Bhavan, New Delhi, India, 1981.

[5] Masters K., Spray drying handbook, Longman scientific and technical Publishers, New York, USA, 1991.

[6] Mathur B.N., Global status and scope of condensed and dried milk industry and its impact on India, in: Compendium on advances in condensed and dried milks, Center for Advanced Studies, Dairy Technol. Div., Natl Dairy Inst., Karnal, India, 1999, pp. 1-9.

[7] Mettler A.E., Chemical and physical aspects of powder quality, in: Milk and Whey Powders, The Society of Dairy Technology, Middlesex, UK, 1980, pp. 92-116.

[8] Salunthe D.K., Deshpande S.S., Foods of plant origin-production, technical and human nutrition, AVI Publications, New York, USA, 1991.

[9] Sandhu J.S., Chemical quality of raw milk for condensed milk systems, Centre for Advanced Studies, Dairy Technol. Division, Natl. Dairy Res. Inst., Karnal, India, 1999, pp. 10-13.

[10] Snedecor G.W., Cochran W.G., Statistical Methods, Oxford and IBH publishing company, 1983.

[11] Strakov V.V., Favstova V.N., Increasing spray drying rate and dried milk quality by higher degree of pre-concentration. Trudy uses, Nauchno-issled Inst. Moloch. Prom. 27 (1970) 92-99.

[12] Upadhyay K.A., Physico-chemical and functional properties of milk powders, in: Compendium on advances in condensed and dried milks, Center for Advanced Studies, Dairy Technol. Div., Natl. Dairy Inst., Karnal, India, 1999, pp. 59-81. 